\title{
KONGRESSKALENDER
}

\section{November 2017}

15.-18. 11.2017 Philadelphia, Pennsylvania (USA)

American Society of Criminology Annual Meeting

Crime, Legatimacy and Reform Fifty Years after the President's Commission

Philadelphia Marriott Downtown Information: http://www.asc41.com/ annualmeeting.htm

\section{Dezember 2017}

04.-06. 12. 2017 Nürnberg, Caritas-Pirckheimer-Haus Arbeitskreis Sozialtherapeutische Anstalten im Justizvollzug e.V. Überregionale Fachtagung Information: www.sotha.de

\section{März 2018}

07.-09.03.2018, Lippstadt-Eickelborn 33. Eickelborner Fachtagung zu Fragen der Forensischen Psychiatrie Dr. N. Saimeh

Kontaktadresse: Michaela.Riepe@ wkp-lwl.org Information: www.lwl-forensik-lippstadt.de

Online publiziert: 11. September 2017

(C) Springer-Verlag GmbH Deutschland 2017

\section{April 2018}

09.-11.04. 2018, Potsdam-Griebnitzsee 19. Basiskurs Forensische Psychiatrie: Schwerpunkt Kriminalprognose Dr. F. Wendt, Prof. Dr. H.-L. Kröber Zentrum für Forensisch- Psychiatrische Begutachtung

Information: www.zfpb.de; kroeber@zfpb.de

\section{Mai 2018}

11.05.2018, Dresden

23. Dresdner Frühjahrstagung

für Forensische Psychiatrie

Dr. Lange, Prof. Dr. Bauer, Dr. Lammel, Dr. Sutarski

Information: www.forensik-dresden.de

30.05.-01.06.2018, Zürich, Schweiz

10. Internationales Symposium

Forensische Psychiatrie

World Trade Center

Prof. Endrass, Dr. Rossegger, Prof. Urbaniok

Information: www.forensiktagung.ch

\section{Juni 2018}

12.06.-14.06.2017, Antwerpen, Belgien $1^{\text {th }}$ Annual IAFMHS Conference Forensic Mental Health Services Information: www.iafmhs.org

15.06.2018, Berlin-Dahlem

22. Berliner Junitagung für Forensische Psychiatrie und Psychologie Forensische Psychiatrie Psychologie Berlin e. V. (FPPB) \& Institut für Forensische Psychiatrie der Charité Information: www.forensik-berlin.de (Veranstaltungen)

\section{August 2018}

28.-31.08. 2018, Vilnius, Litauen $1^{\text {th }}$ Conference International Association for the Treatment of Sexual Offenders (IATSO)

Information: www.iatso.org

\section{Oktober 2018}

Oktober 2018, München

33. Herbsttagung für Forensische Psychiatrie

Abteilung für Forensische Psychiatrie der Universität München

Information: www.forensik-muenchen.de

17.-20.10.2018, Vancouver, BC, Canada Association for the Treatment of Sexual Abusers (ATSA) Hyatt Regency Vancouver Information: http://www.atsa.com/futureatsa-conferences

25.-28. 10.2018, Austin, Texas (USA) American Academy of Psychiatry and the Law $4^{\text {th }}$ Annual Meeting (with APA) JW Marriott Austin Information: www.AAPL.org

Ein internationaler kriminologischer Kongresskalender findet sich unter http://www.asc41.com/caw.html Hinweise für den Kongresskalender bitte an: mail@hlkroeber.de 